\title{
REMOTE SENSING EXTRACTION OF STOPES AND TAILINGS PONDS IN AN ULTRA-LOW-GRADE IRON MINING AREA
}

\author{
Baodong $\mathrm{Ma}^{1 *}$, Yuteng $\mathrm{Chen}^{1}$, Xuexin $\mathrm{Li}^{1}$, Lixin $\mathrm{Wu}^{2}$ \\ ${ }^{1}$ Institute for Geoinformatics \& Digital Mine Research, Northeastern University, Shenyang 110819, P. R. China \\ mabaodong_rs@126.com \\ ${ }^{2}$ School of Geoscience and Info-Physics, Central South University, Changsha, 410083, P.R. China
}

KEY WORDS: Ultra-low-grade iron, mining area, remote sensing, spectral and thermal characteristics, stope and tailings pond

\begin{abstract}
:
With the development of economy, global demand for steel has accelerated since 2000, and thus mining activities of iron ore have become intensive accordingly. An ultra-low-grade iron has been extracted by open-pit mining and processed massively since 2001 in Kuancheng County, Hebei Province. There are large-scale stopes and tailings ponds in this area. It is important to extract their spatial distribution information for environmental protection and disaster prevention. A remote sensing method of extracting stopes and tailings ponds is studied based on spectral characteristics by use of Landsat 8 OLI imagery and ground spectral data. The overall accuracy of extraction is $95.06 \%$. In addition, tailings ponds are distinguished from stopes based on thermal characteristics by use of temperature image. The results could provide decision support for environmental protection, disaster prevention, and ecological restoration in the ultra-low-grade iron ore mining area.
\end{abstract}

\section{BACKGROUND}

With the rapid development of the world steel industry in the early 21 st century, especially in China, iron ore market has undergone profound changes (Sonter et al., 2014; Yellishetty et al., 2010). In this context, a new type of iron, ultra-low-grade iron ore with $10 \%-20 \%$ total iron (TFe) has been developed massively in Kuancheng County, Hebei Province (Li et al., 2015; Zhang et al, 2014; Shi et al, 2015; Li et al, 2012). Changhe Mining Area is an important mining area in the region, and has proven reserves of more than 2.3 billon tons of ultralow-grade iron ore (Ma et al, 2017).

Due to the high concentration ratio $(10: 1)$, the ore mining capacity and the amount of ultra-low-grade iron ore is far higher than that of other minerals. As a result, large-scale stopes and tailings ponds are created in the mining area. Tailings pond and stope may produce serious safety threat and environmental pollution (Coulibaly et al, 2017; Stovern et al, 2015). Accurate and timely monitoring of stopes and tailings ponds is of great significance to guide the regional environmental governance, disaster prevention, and ecological restoration ( $\mathrm{Hu}$ et al, 2017; Mohamed et al, 2008; Zornoza et al, 2013). However, less research has been done for extracting the above information by use of remote sensing images. Therefore, extraction method of stopes and tailings ponds in the ultra-low-grade iron mining area is studied based on ground spectral analysis and remote sensing images in this study.

\section{STUDY AREA AND DATA}

\subsection{Study area}

Changhe Mining area (about $150 \mathrm{~km}^{2}$ ) is located in Kuancheng County, Hebei Province, China (Figure 1). At present, annual production of iron powder is more than 10 million tons in this area. This area is covered by dense vegetation. It has a continental monsoon climate with an annual precipitation of $662.5 \mathrm{~mm}$ and an annual temperature of $8.7^{\circ} \mathrm{C}$.

\subsection{Ground spectral data}

Spectra of typical objects in the study area, i.e., vegetation, soil, water, iron ore in stopes and tailings in tailings ponds, were collected by SVC spectrometer when the Landsat 8 OLI imagery was acquired.

\subsection{Remote sensing data}

Landsat 8 OLI image (path 122 and row 32), acquired on August 9, 2013, was selected for the iron stope and tailings pond detection (downloaded from USGS, http://glovis.usgs.gov/). Its spatial resolution is $30 \mathrm{~m}$ in multispectral bands, $15 \mathrm{~m}$ in panchromatic band and $60 \mathrm{~m}$ in thermal infrared bands. The image was atmospherically corrected to surface reflectance by using the Fast Line-of-Slight Atmospheric Analysis of Spectral Hypercubes (FLAASH) module of ENVI software. Then the image was geometrically registered. GeoEye high-resolution image is used to verify the Landsat results.

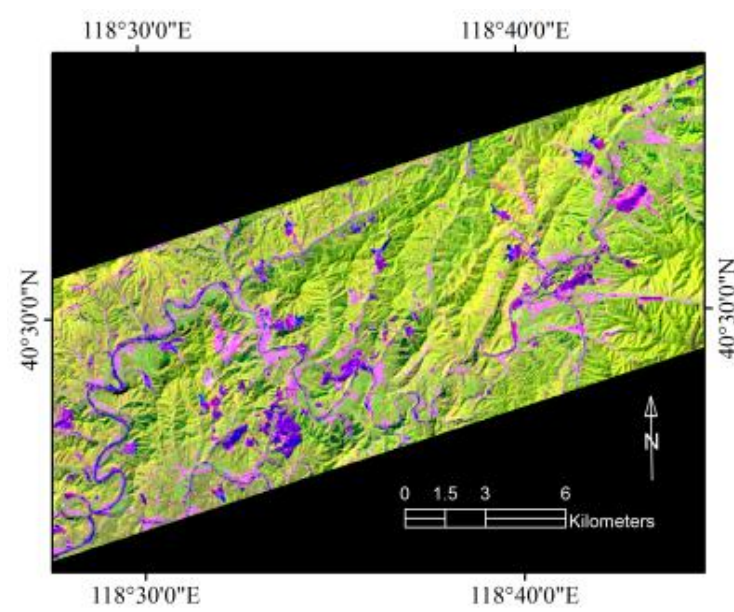

Fig.1 Landsat 8 OLI image of the study area (False-color composite RGB 654, acquired on August 9, 2013) 


\section{METHODS AND RESULTS}

3.1 Design of Ultra-low-grade Iron Index (ULII) for extracting stopes and tailings ponds

Totally, compared with other ground objects, reflectivity of iron ore and tailings is OLI $3 \geqslant$ OLI4, OLI7 $>$ OLI6. However, there are not significant spectral differences between tailings and iron ore (Figure 2).

The OLI3, 4, 6 and 7 bands were selected to construct Ultralow-grade Iron Index (ULII).

$$
\mathrm{ULII}=(\mathrm{OLI} 3 * \mathrm{OLI} 7) /(\mathrm{OLI} 4 * \mathrm{OLI} 6)
$$

where OLI3, OLI4, OLI6 and OLI7 represent the reflectivity of objects in OLI band 3, 4, 6, and 7 respectively. In the ULII map, stopes and tailings ponds are prominent, and the other objects (vegetation, buildings, water and so on) are suppressed (Figure $3 \mathrm{a})$. The value 0.84 was selected as a threshold for extraction of stopes and tailings ponds (Figure 3b). Compared with highresolution GeoEye image, it was found that the overall accuracy was $95.06 \%$ (Figure 3c).

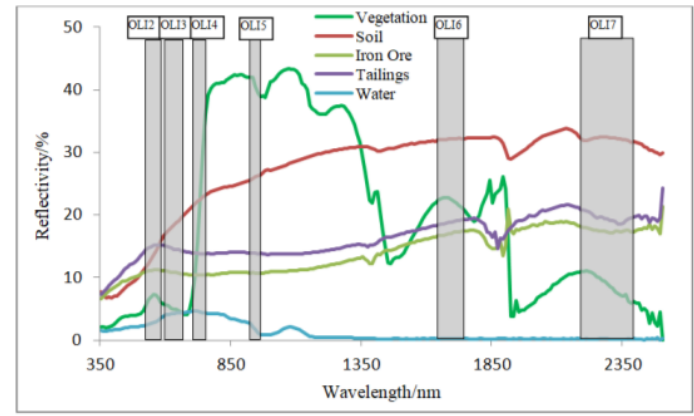

Fig.2 Spectral characteristics of typical features in the study area
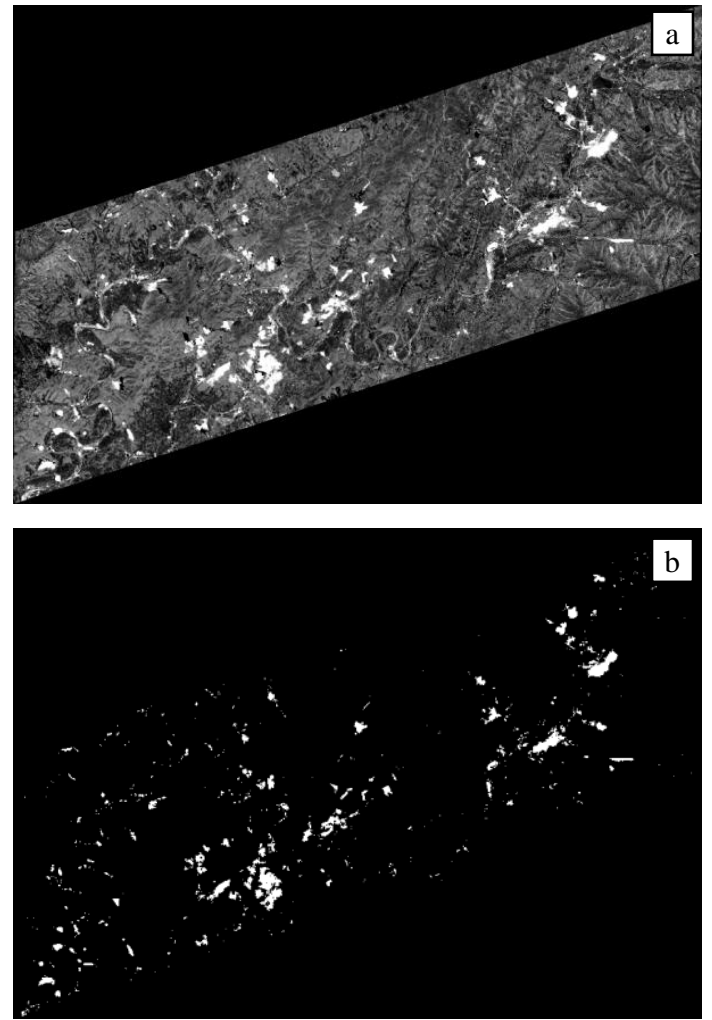

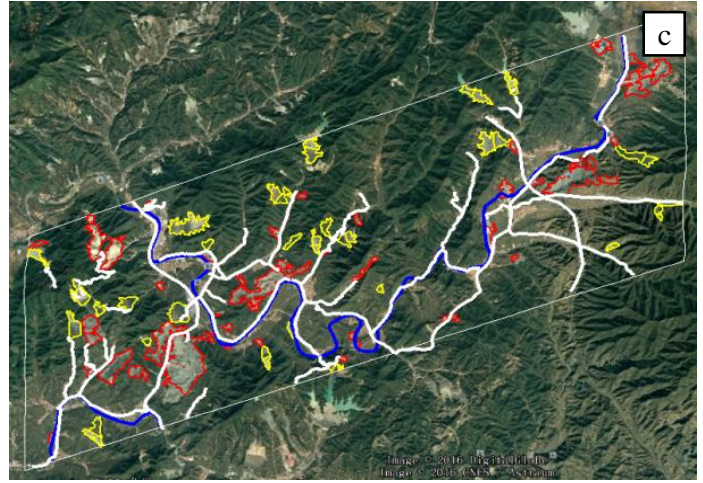

Fig. 3 Extracting map of stopes and tailings ponds based on Ultra-low-grade Iron Index (ULII) in the study area. a) ULII image; b) Stopes and tailings ponds (in white color) extracted with the threshold 0.84; c) High-resolution GeoEye image

(Tailings pond is yellow, and stope is red).

\subsection{Distinguishing tailings ponds from stopes based on} thermal characteristics

(1) Thermal characteristics of stope and tailings pond

Land surface temperature is retrieved from the thermal infrared band of remote sensing data (Figure 4). At the image acquisition time (10:49 am on August 9, 2013), the average temperature of stopes and tailings ponds was $31.48 \mathrm{C}$, and the average temperature of the other regions was 27.15 C. The temperature difference is 4.33 C. It shows the heat island effect in stopes and tailings ponds is significant in this area.

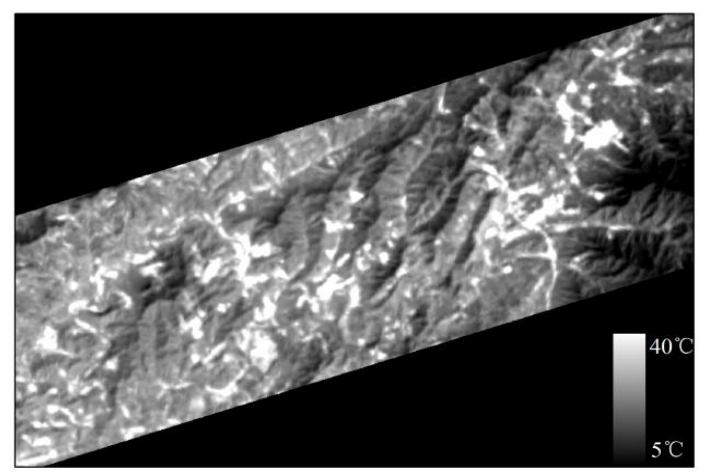

Fig. 4 Temperature map of the study area

(2) Characteristics of annular heat island in tailings ponds

There is also temperature difference between the tailings pond and the stope. The temperature of the tailings pond is higher than the stope on the whole. For spatial distribution, the distribution of temperature is more uniform in the stope, and the temperature of the tailings pond is annular and the central temperature is the highest (Figure 5). Tailings pond and stope can be distinguished based on the characteristics of the annular heat island in the tailings pond (Figure 6).

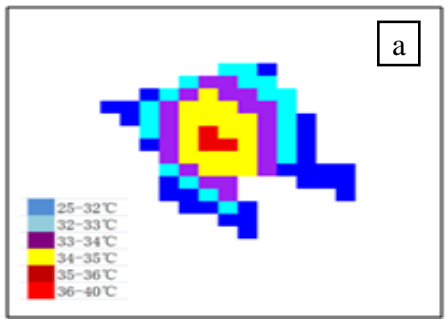




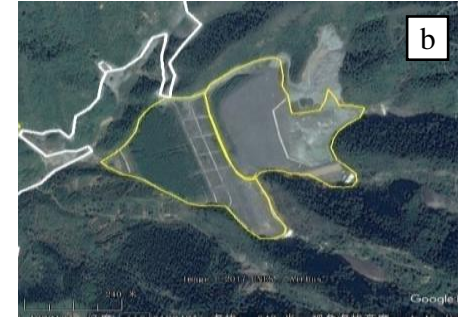

Fig. 5 Temperature distribution of tailings pond. a) Temperature image of tailings pond; b) GeoEye iamge of tailings ponds.

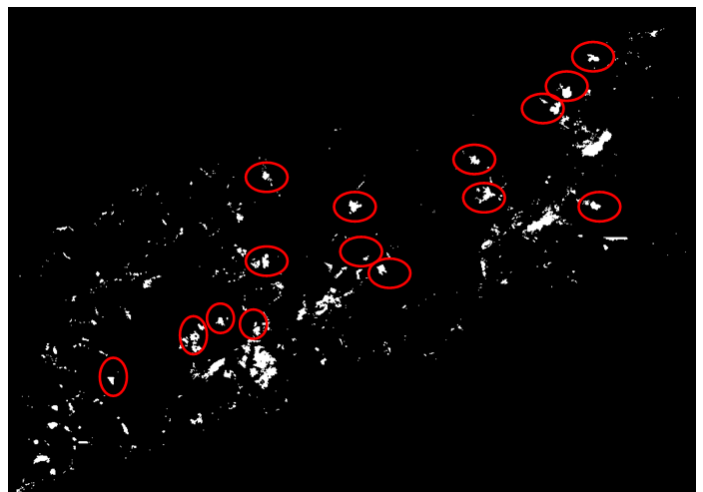

Fig. 6 Extracted tailings ponds (in red circle) based on thermal characteristics

\section{CONCLUSIONS}

(1) Based on spectral characteristics of tailings in tailings ponds and iron ore in stopes, ULII (Ultra-low-grade Iron Index) was designed to extract tailings ponds and stopes in Changhe mining area by using Landsat images. The extraction is realized by the use of a threshold of 0.84 .

(2) Average temperature in tailings ponds and stopes is $31.48 \mathrm{C}$, and it is higher than other regions with 4.33 C. The heat island effect is obvious in tailings ponds and stopes. The temperature distribution in tailings ponds is annular, and the central temperature is the highest. Based on this feature, tailings ponds can be distinguished from stopes.

(3) The method is useful for the land cove/land use change monitoring in the ultra-low-grade iron mining area. Remote sensing extraction results could provide decision support for environmental protection, disaster prevention, and ecological restoration in the ultra-low-grade iron ore mining area.

\section{ACKNOWLEDGEMENTS}

This research is jointly supported by the Fundamental Research Funds for the Central Universities (N160104006), and the National Natural Science Foundation of China (41201359).

\section{REFERENCES}

Coulibaly, Y., Belem, T., Cheng, L., 2017. Numerical analysis and geophysical monitoring for stability assessment of the Northwest tailings dam at Westwood Mine. International Journal of Mining Science and Technology . 27 (4), pp.701710 .

Hu, X., Oommen, T., Lu, Z., 2017. Consolidation settlement of Salt Lake County tailings impoundment revealed by timeseries InSAR observations from multiple radar satellites.
Remote Sensing of Environment. 202, pp.199-209.

Li, H.-M., Li, L.-X., Yang, X.-Q., Cheng, Y.-B., 2015. Types and geological characteristics of iron deposits in China. Journal of Asian Earth Sciences. 103, pp.2-22.

Li, L. X., Li, H. M., Wang, D. Z., Liu, M. J., Yang, X. Q., Chen, J., 2012. Ore genesis and ore-forming age of the Tiemahabaqin ultra-low-grade iron deposit in Chengde, Hebei Province, China. Rock Miner. Anal .31 (5), pp.898-905.

Ma, B.D., Pu, R., Wu, L., Zhang, S., 2017. Vegetation Index Differencing for Estimating Foliar Dust in an Ultra-LowGrade Magnetite Mining Area Using Landsat Imagery. Ieee Access. 5, pp.8825-8834.

Mohamed, M. H., Wilson, L. D., Headley, J. V., 2008. Novel materials for environmental remediation of tailing pond waters containing naphthenic acids. Process Safety and Environmental Protection. 86 (4), pp.237-243.

Shi, S., Zhang M., Tan M., 2015. Recovery of phosphorite from coarse particle magnetic ore by flotation. International Journal of Mineral Processing. 142, pp.10-16.

Sonter, L. J., Barrett, D. J., Soares-Filho, B. S., Moran, C. J., 2014. Global demand for steel drives extensive land-use change in Brazil's Iron Quadrangle. Global Environmental Change. 26, pp, 63-72.

Stovern, M., Rine, K., Russell, M., 2015. Development of a dust deposition forecasting model for mine tailings impoundments using in situ observations and particle transport simulations. Aeolian Research. 18, pp.155-167.

Yellishetty, M., Ranjith, P. G., Tharumarajah, A., 2010. Iron ore and steel production trends and material flows in the world: Is this really sustainable? Resources, conservation and recycling. 54 (12), pp.1084-1094.

Zhang, Z., Hou, T., Santosh, M., Li, H., Li, J., Zhang, Z., Song, X., Wang, M., 2014. Spatio-temporal distribution and tectonic settings of the major iron deposits in China: An overview. Ore Geology Reviews. 57, pp. 247-263.

Zornoza, R., Faz, Á., Carmona, D. M., 2013. Carbon mineralization, microbial activity and metal dynamics in tailing ponds amended with pig slurry and marble waste. Chemosphere. 90 (10), pp.2606-2613. 